\title{
Pregnancy outcomes in women with
}

\section{cardiovascular disease: evolving trends over} 10 years in the ESC Registry Of Pregnancy And Cardiac disease (ROPAC)

\author{
Jolien Roos-Hesselink ${ }^{1,2 *}$, Lucia Baris ${ }^{1}$, Mark Johnson ${ }^{3}$, Julie De Backer", \\ Catherine Otto ${ }^{5}$, Ariane Marelli $i^{6}$, Guillaume Jondeau ${ }^{7}$, Werner Budts ${ }^{8}$, \\ Jasmine Grewal', Karen Sliwa ${ }^{10}$, William Parsonage ${ }^{11}$, Aldo P. Maggioni ${ }^{2,12}$, \\ Iris van Hagen ${ }^{1}$, Alec Vahanian ${ }^{2,7}$, Luigi Tavazzi ${ }^{13}$, Uri Elkayam ${ }^{14}$, \\ Eric Boersma ${ }^{1}$, and Roger Hall ${ }^{15}$; on behalf of the ROPAC Investigators
}

\begin{abstract}
${ }^{1}$ Department of Cardiology, Erasmus Medical Center, PO Box 2040, 3000 CA Rotterdam, The Netherlands; ${ }^{2}$ EURObservational Research Programme, European Society of Cardiology, 2035 route des Colles les Templiers, 06903 Sophia Antipolis, France; ${ }^{3}$ Department of Obstetric Medicine, Imperial College London, Kensington, London SW7 $2 A Z$, UK; ${ }^{4}$ Department of Cardiology, Ghent University Hospital, Corneel Heymanslaan 10, 9000 Ghent, Belgium; ${ }^{5}$ Department of Cardiology, UW School of Medicine, 1959 NE Pacific St, Seattle, WA 98195, USA; ${ }^{6}$ Department of Cardiology, McGill University Faculty of Medicine, 3605 Rue de la Montagne, Montréal, QC H3G 2M1, Canada; ${ }^{7}$ Department of Cardiology, Bichat-Claude Bernard Hospital, 46 Rue Henri Huchard, 75877 Paris, France; ${ }^{8}$ Department of Cardiology, University Hospitals Leuven, Herestraat 49, 3000 Leuven, Belgium; ${ }^{9}$ Department of Cardiology, University of British Columbia, Faculty of Medicine, 2312 Pandosy St, Kelowna, BC V1Y $1 T 3$, Canada; ${ }^{10}$ Hatter Institute for Cardiovascular Research in Africa, Faculty of Health Sciences, University of Cape Town, Private Bag X3 7935, Observatory, South Africa; ${ }^{11}$ Department of Cardiology, Royal Brisbane and Women's Hospital, Cnr Butterfield St and Bowen Bridge Road, Herston, QLD 4029, Australia; ${ }^{12}$ National Association of Hospital Cardiologists Research Center (ANMCO), Florence, Italy; ${ }^{13}$ Department of Cardiology, Maria Cecilia Hospital, Via Madonna di Genova, 1, 48033 Cotignola RA, Italy; ${ }^{14}$ Department of Obstetrics and Gynaecology, University of Southern California, Keck School of Medicine, 1975 Zonal Ave, Los Angeles, CA 90033, USA; ${ }^{15}$ Department of Cardiology, University of East Anglia, Faculty of Medicine, Norwich Research Park, Norwich NR4 7TJ, UK
\end{abstract}

Received 14 December 2018; revised 17 January 2019; editorial decision 22 February 2019; accepted 8 March 2019

Aims

Reducing maternal mortality is a World Health Organization (WHO) global health goal. Although maternal deaths due to haemorrhage and infection are declining, those related to heart disease are increasing and are now the most important cause in western countries. The aim is to define contemporary diagnosis-specific outcomes in pregnant women with heart disease.

Methods From 2007 to 2018, pregnant women with heart disease were prospectively enrolled in the Registry Of Pregnancy and results And Cardiac disease (ROPAC). Primary outcome was maternal mortality or heart failure, secondary outcomes were other cardiac, obstetric, and foetal complications. We enrolled 5739 pregnancies; the mean age was 29.5 . Prevalent diagnoses were congenital (57\%) and valvular heart disease (29\%). Mortality (overall $0.6 \%$ ) was highest in the pulmonary arterial hypertension (PAH) group (9\%). Heart failure occurred in $11 \%$, arrhythmias in $2 \%$. Delivery was by Caesarean section in $44 \%$. Obstetric and foetal complications occurred in $17 \%$ and $21 \%$, respectively. The number of high-risk pregnancies (mWHO Class IV) increased from 0.7\% in 2007-2010 to 10.9\% in 2015-2018. Determinants for maternal complications were pre-pregnancy heart failure or New York Heart Association >II, systemic ejection fraction <40\%, mWHO Class 4, and anticoagulants use. After an increase from 2007 to 2009 , complication rates fell from $13.2 \%$ in 2010 to $9.3 \%$ in 2017 .

Conclusion Rates of maternal mortality or heart failure were high in women with heart disease. However, from 2010, these rates declined despite the inclusion of more high-risk pregnancies. Highest complication rates occurred in women with $\mathrm{PAH}$.

\footnotetext{
* Corresponding author. Tel: +31 (0)10 7032432, Email: j.roos@erasmusmc.nl

(c) The Author(s) 2019. Published by Oxford University Press on behalf of the European Society of Cardiology.

This is an Open Access article distributed under the terms of the Creative Commons Attribution Non-Commercial License (http://creativecommons.org/licenses/by-nc/4.0/), which permits non-commercial re-use, distribution, and reproduction in any medium, provided the original work is properly cited. For commercial re-use, please contact journals.permissions@oup.com
} 


\section{Introduction}

Maternal heart disease complicates between $1 \%$ and $4 \%$ of pregnancies, and accounts for up to $15 \%$ of maternal deaths. ${ }^{1,2}$ According to the most recent statistics from the World Health Organization (WHO), maternal mortality in developed economies is around 12 per 100000 live births (0.012\%) and 239 per 100000 live births $(0.2 \%)$ in emerging economies, with large disparities both between and within countries. ${ }^{3}$ While leading causes such as haemorrhage and infection are declining, mortality due to maternal heart disease is increasing ${ }^{2,4,5}$ and in developed countries, heart disease is now the leading cause. The burden of maternal heart disease is expected to increase due to improved survival of women with congenital heart disease $(\mathrm{CONHD})$ and the trend to delay motherhood, with the associated rise in comorbidities such as metabolic syndrome. Thus, heart disease may become an even greater contributor to maternal deaths worldwide. ${ }^{2}$

Research is difficult to perform in the field of heart disease and pregnancy and observational studies such as CARPREG and ZAHARA have been the primary source of evidence. ${ }^{6-9}$ Large prospective registries were needed to improve the quality and level of knowledge relating to this growing population. Therefore, in 2007, the EURObservational Research Programme (EORP) of the European Society of Cardiology (ESC) established the Registry Of Pregnancy And Cardiac disease (ROPAC). This important data source assembles granular clinical data on large numbers of pregnant patients with heart disease from real-life daily practice, informing our understanding of the outcomes in this population with the ultimate goal of improving patient outcomes. An interim analysis of the first 1321 patients was reported in $2013^{10}$ and an overview of the full registry is presented here.

The aims of the current study are to provide contemporary information on the impact of a wide range of cardiovascular diseases on maternal and foetal mortality and morbidity and identify key areas where current management can be improved.

\section{Methods}

\section{Study design}

The Registry Of Pregnancy And Cardiac disease (ROPAC) is an international, prospective, observational registry of pregnant women with CONHD, valvular heart disease (VHD), cardiomyopathy (CMP), or ischaemic heart disease (IHD). Pregnancies were included prospectively from January 2007 until January 2018. From 2013, patients with pulmonary arterial hypertension (PAH) or aorta pathology (AOP) were also enrolled. An interim analysis of the first 1321 pregnancies (PREG1) was published in 2013. Comparisons were made between the PREG1 and the data collected from 2011 onwards (PREG2). We included data from all pregnancies up to 1 week post-partum. Women with a primary diagnosis of $\mathrm{PAH}$ or $\mathrm{AOP}$ were excluded from the analysis of trends over time because they have not been enrolled in ROPAC from the start of the registry.

\section{Data, definitions, study endpoints, and statistical analysis}

The study protocol, methods, and the outcomes of the first 1321 pregnancies included were published in 2013. ${ }^{10}$ The primary endpoint was maternal mortality and/or heart failure. Information on data, definitions, endpoints, and statistical methods can be found in the Supplementary material online, Appendix.

\section{Results}

A total of 5739 pregnancies were recruited from 138 centres in 53 countries. The list of participating centres is given in the Supplementary material online, Appendix. Sixty percent of women were from developed countries. The mean maternal age was 29.5 years, and $45 \%$ were nulliparous. There were 96 twin pregnancies (1.7\%). The baseline characteristics for PREG1, PREG2, and the total cohort are presented in Table 1. Details of diagnosis are shown in Supplementary material online, Figure S1. There were missing data in $1.7 \%$ of baseline variables.

Table 2 summarizes the cardiovascular, obstetric, and foetal outcomes, for PREG1, PREG2, and the total cohort. In Supplementary material online, Tables S1-S3, the baseline characteristics and outcomes are summarized per diagnostic group and divided in emerging and developed countries and in Supplementary material online, Table S4, the differences in characteristics and outcome are compared between women who have undergone pre-conceptional counselling and those who have not.

The PREG1 and the PREG2 cohorts differed significantly with respect to the percentage nulliparous women (49.2\% vs. $43.5 \%$, $P<0.001)$, women from emerging countries $(21.3 \%$ vs. $45.3 \%$, $P<0.001)$, women with a diagnosis of CONHD (62.0\% vs. $56.0 \%$, $P<0.001)$, prior interventions (61.3\% vs. 53.2\%, $P<0.001)$, and prepregnancy cardiac medication use $(20.4 \%$ vs. $40.8 \%, P<0.001)$. Also, the distribution of women in the different $\mathrm{mWHO}$ classes differed significantly, the most remarkable difference being the percentage of women in $\mathrm{mWHOIV}$.

\section{Maternal cardiovascular outcome and clinical determinants of study endpoint}

Maternal mortality and/or heart failure occurred in 629 pregnancies (11\%), with maternal death in 34 women $(0.6 \%)$. In four cases, the cause of death was unknown and five patients died from non-cardiac causes, four of these being septic shock. Refractory heart failure was the cause of death in 15 patients, five of which were related to severe PAH. Four patients died from complications of mechanical valve thrombosis, two from endocarditis, two patients from primary cardiac arrest with ventricular fibrillation, and two other patients from haemodynamic complications following abortion and pulmonary embolism, respectively. 
Table I Baseline characteristics of PREG1 and PREG2 cohorts and the total cohort

\begin{tabular}{|c|c|c|c|c|}
\hline & $\begin{array}{l}\text { Total cohort } \\
(n=5739)\end{array}$ & $\begin{array}{l}\text { PREG1 cohort } \\
(n=1321)\end{array}$ & $\begin{array}{l}\text { PREG } 2 \text { cohort } \\
(n=4418)\end{array}$ & $P$-value \\
\hline \multicolumn{5}{|l|}{ Demographics } \\
\hline Age, mean (SD) & $29.5(5.6)$ & $29.2(5.7)$ & $29.6(5.6)$ & 0.01 \\
\hline Nulliparity & $2573(44.8 \%)$ & $652(49.2 \%)$ & $1921(43.5 \%)$ & $<0.001$ \\
\hline Emerging country & 2281 (39.7\%) & $282(21.3 \%)$ & 1999 (45.3\%) & $<0.001$ \\
\hline \multicolumn{5}{|l|}{ Diagnosis } \\
\hline Congenital heart disease & 3295 (57.4\%) & $822(62.0 \%)$ & $2473(56.0 \%)$ & $<0.001$ \\
\hline Valvular heart disease & 1648 (28.7\%) & $341(25.7 \%)$ & 1307 (29.6\%) & 0.01 \\
\hline Cardiomyopathy & $438(7.6 \%)$ & $91(6.9 \%)$ & $347(7.9 \%)$ & 0.23 \\
\hline Pregnancy-induced during current pregnancy & $23(5.3 \%)^{\mathrm{a}}$ & $0(0 \%)$ & $23(6.6 \%)$ & $<0.001$ \\
\hline Ischaemic heart disease & $95(1.6 \%)$ & $26(2.0 \%)$ & $69(1.6 \%)$ & 0.32 \\
\hline \multicolumn{5}{|l|}{ Pre-pregnancy clinical characteristics } \\
\hline Current smoking & $228(4 \%)$ & $45(3.3 \%)$ & $183(4.1 \%)$ & 0.34 \\
\hline Hypertension & $380(7 \%)$ & $88(6.7 \%)$ & $292(6.6 \%)$ & 0.89 \\
\hline History of diabetes mellitus & $90(2 \%)$ & $21(1.6 \%)$ & $69(1.6 \%)$ & 1 \\
\hline History of atrial fibrillation & $106(2 \%)$ & $24(1.8 \%)$ & $82(1.9 \%)$ & 0.91 \\
\hline Signs of heart failure & $596(11 \%)$ & $136(10.3 \%)$ & $460(10.4 \%)$ & 0.88 \\
\hline Prior intervention & 3160 (55\%) & $812(61.3 \%)$ & $2348(53.2 \%)$ & 0.08 \\
\hline NYHA class & & & & 0.35 \\
\hline I & 4207 (73.3\%) & 937 (70.7\%) & 3270 (74.1\%) & \\
\hline ॥ & 1191 (20.8\%) & $323(24.5 \%)$ & $868(19.7 \%)$ & \\
\hline III & $176(3.1 \%)$ & $40(3.0 \%)$ & $136(3.1 \%)$ & \\
\hline IV & $28(0.5 \%)$ & $4(0.3 \%)$ & $24(0.5 \%)$ & \\
\hline Cardiac medication & 2069 (36.1\%) & $270(20.4 \%)$ & 1799 (40.8\%) & $<0.001$ \\
\hline $\mathrm{mWHO}$ class & & & & 0.05 \\
\hline I & 1185 (20.6\%) & $284(21.4 \%)$ & $901(20.4 \%)$ & \\
\hline ॥ & $828(14.4 \%)$ & $226(17.1 \%)$ & $602(13.6 \%)$ & \\
\hline$\|-I I I$ & $2698(47.0 \%)$ & $720(54.3 \%)$ & 1978 (44.8\%) & \\
\hline III & $593(10.3 \%)$ & $88(6.6 \%)$ & $505(11.4 \%)$ & \\
\hline IV & 407 (7.1\%) & $7(0.5 \%)$ & $400(9.1 \%)$ & \\
\hline
\end{tabular}

$P$-values were calculated between the PREG1 and PREG2 cohorts (independent samples $t$-test and $\chi^{2}$ tests where appropriate).

apercentage of cardiomyopathies.

Heart failure complicated 611 pregnancies (11\%), of which 44 (7\%) occurred solely postpartum. In women with a mechanical valve, 22 (7\%) pregnancies were complicated by valve thrombosis, which was lethal in four (18\%). Of the six women with known valvular replacement surgery none died, while of the two women with known thrombolytic therapy one died due to intracerebral haemorrhage. Supplementary material online, Table S5 shows the women with valve thrombosis and their outcome. In the AOP group, aortic dissection occurred in four (1.8\%), at a mean of 34 weeks gestation. In Figure 1, the occurrence of cardiovascular events is summarized for the different diagnosis groups and in Supplementary material online, Figure S2, it is subdivided for the additional sub-groups. Within PREG1 were significantly less thrombotic events compared with PREG2 (0.5\% vs. $1.8 \%, P=0.006)$.

In Figure 2, the results from the regression analyses are shown for the primary outcome for the total cohort. Pre-pregnancy New York Heart Association (NYHA) $>\|$, systemic ventricular ejection fraction (EF) of $<40 \%$, signs of heart failure, $\mathrm{mWHO}$ IV, and anticoagulation use were independent predictors of the occurrence of death/heart failure.

\section{Study endpoints over time}

The incidence of death/heart failure changed over time (Figure 3). Assuming a linear trend since 2007, the annual incidence decreased by $0.8 \%$ year $(P<0.001)$. However, our data suggest that there was an early increase until 2010, with a subsequent annual decrease of 1.3\%/year $(P<0.001)$ thereafter. Noteworthy, this decline was reached, while the percentage of $\mathrm{mWHO}$ IV patients increased from around $1 \%$ in the first years up to $10 \%$ in the last years (Supplementary material online, Figure S3). Time trends were similar in the three main diagnostic groups, but most pronounced in CMP. Supplementary material online, Figure S5 shows trend analyses for emerging and developed countries.

\section{Obstetric and foetal outcome}

A total of 992 pregnancies (17\%) were complicated by obstetric events during pregnancy. Emergency caesarean section was performed in 537 pregnancies (9\%), 84 (16\%) were for cardiac reasons. Preeclampsia occurred in $3 \%$ and was seen more commonly in 
Table 2 Outcomes of PREG1 and PREG2 cohorts and the total cohort

\begin{tabular}{|c|c|c|c|c|c|c|c|}
\hline & $\begin{array}{l}\text { Total cohort } \\
(n=5739)\end{array}$ & $95 \% \mathrm{Cl}$ & $\begin{array}{l}\text { PREG1 cohort } \\
(n=1321)\end{array}$ & $95 \% \mathrm{Cl}$ & $\begin{array}{l}\text { PREG2 cohort } \\
(n=4418)\end{array}$ & $95 \% \mathrm{Cl}$ & $P$-value \\
\hline \multicolumn{8}{|l|}{ Cardiovascular outcome } \\
\hline Maternal mortality and/or heart failure & $629(11.0 \%)$ & $10.2-11.8 \%$ & $161(12.2 \%)$ & $10.5-14.1 \%$ & $468(10.6 \%)$ & $9.7-11.5 \%$ & 0.11 \\
\hline Maternal mortality & $34(0.6 \%)$ & $0.4-0.8 \%$ & $9(0.7 \%)$ & $0.4-0.13 \%$ & $25(0.6 \%)$ & $0.4-0.8 \%$ & 0.63 \\
\hline Heart failure event & $611(10.6 \%)$ & $9.9-11.5 \%$ & $153(11.5 \%)$ & $10.0-13.4 \%$ & $458(10.3 \%)$ & $9.5-11.3 \%$ & 0.29 \\
\hline Supraventricular arrhythmia & $95(1.7 \%)$ & $1.4-2.0 \%$ & $11(0.9 \%)$ & $0.5-0.15 \%$ & $84(1.9 \%)$ & $1.5-2.3 \%$ & 0.06 \\
\hline Ventricular arrhythmia & $90(1.6 \%)$ & $1.3-1.9 \%$ & $27(2.0 \%)$ & $1.4-3.0 \%$ & $63(1.4 \%)$ & $1.1-1.8 \%$ & 0.30 \\
\hline Thrombotic event & $87(1.5 \%)$ & $1.2-1.9 \%$ & $6(0.5 \%)$ & $0.2-1.0 \%$ & $81(1.8 \%)$ & $1.5-2.3 \%$ & 0.006 \\
\hline Aortic dissection & $5(0.1 \%)$ & $0.0-0.2 \%$ & $0(0 \%)$ & $0.0-0.3 \%$ & $5(0.1 \%)$ & $0.0-0.3 \%$ & 0.22 \\
\hline \multicolumn{8}{|l|}{ Obstetric outcome } \\
\hline Pregnancy-induced hypertension & $150(2.6 \%)$ & $2.2-3.1 \%$ & $25(2.4 \%)$ & $1.3-2.8 \%$ & $125(2.8 \%)$ & $2.4-3.4 \%$ & 0.57 \\
\hline (Pre-)eclampsia & $159(2.8 \%)$ & $2.4-3.2 \%$ & $44(3.3 \%)$ & $2.5-4.4 \%$ & $115(2.6 \%)$ & $2.2-3.1 \%$ & 0.35 \\
\hline Post-partum haemorrhage & $170(3.0 \%)$ & $2.6-3.4 \%$ & $38(2.9 \%)$ & $2.1-3.9 \%$ & $132(3.0 \%)$ & $2.5-3.5 \%$ & 0.89 \\
\hline Caesarean section & $2681(46.7 \%)$ & $45.4-48.0 \%$ & $538(40.6 \%)$ & $38.1-43.3 \%$ & $2143(48.6 \%)$ & $47.0-50.0 \%$ & $<0.001$ \\
\hline Emergency caesarean section & $766(13.3 \%)$ & $12.5-14.3 \%$ & $204(15.4 \%)$ & $13.6-17.5 \%$ & $562(12.7 \%)$ & $11.8-13.7 \%$ & 0.01 \\
\hline \multicolumn{8}{|l|}{ Foetal outcome } \\
\hline Foetal mortality & $72(1.3 \%)$ & $1.0-1.6 \%$ & $20(1.5 \%)$ & $1.0-2.3 \%$ & $52(1.2 \%)$ & $0.9-1.5 \%$ & 0.56 \\
\hline Neonatal mortality & $33(0.6 \%)$ & $0.4-0.8 \%$ & $8(0.6 \%)$ & $0.3-1.2 \%$ & $25(0.6 \%)$ & $0.4-0.8 \%$ & 0.88 \\
\hline Premature birth & $905(15.8 \%)$ & $14.8-16.7 \%$ & $200(15.1 \%)$ & $13.3-17.2 \%$ & 705 (16.0\%) & $14.9-17.1 \%$ & 0.58 \\
\hline Low apgar scores & 397 (6.9\%) & $6.3-7.6 \%$ & 95 (7.2\%) & $5.9-8.7 \%$ & $282(6.4 \%)$ & $5.7-7.1 \%$ & 0.48 \\
\hline IUGR & $254(4.4 \%)$ & $3.9-5.0 \%$ & 70 (5.3\%) & $4.2-6.6 \%$ & $184(4.2 \%)$ & $3.6-4.8 \%$ & 0.25 \\
\hline Low birth weight & 673 (11.7\%) & $10.9-12.6 \%$ & $12(0.9 \%)$ & $0.5-1.6 \%$ & 661 (15.0\%) & $13.9-16.0 \%$ & $<0.001$ \\
\hline
\end{tabular}

P-values were calculated between the PREG1 and PREG2 cohort ( $\chi^{2}$ tests). All events were monitored between enrolment date (start of pregnancy or first trimester) and 1 week after delivery.

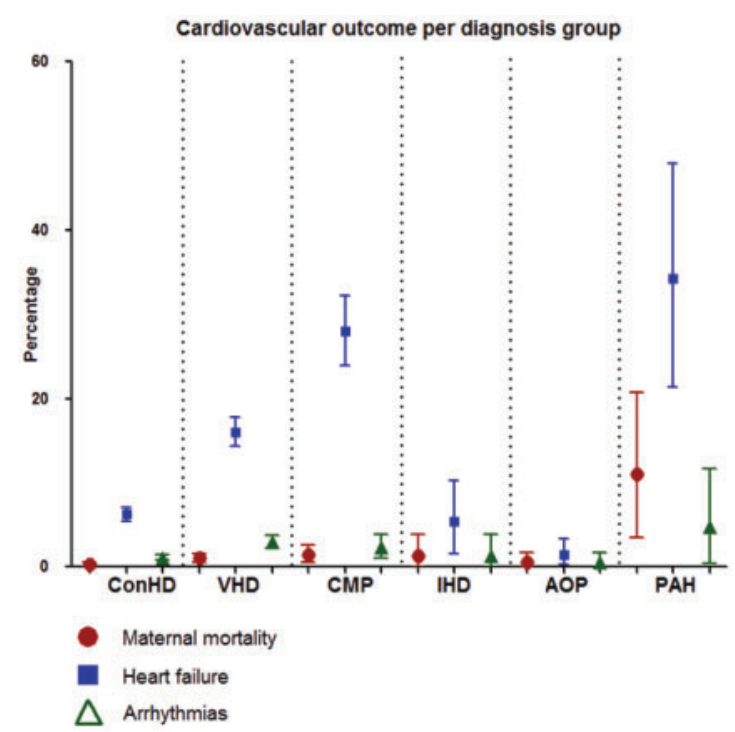

Figure I The occurrence of maternal cardiovascular events for the different diagnosis groups. AOP, aortic pathology; CMP, cardiomyopathy; CONHD, congenital heart disease; IHD, ischemic heart disease; $\mathrm{PAH}$, pulmonary arterial hypertension; $\mathrm{VHD}$, valvular heart disease. patients with CMP and PAH (7\% and 11\%, respectively). In women with peripartum CMP during current pregnancy $(n=23)$, six contemporaneously suffered from preeclampsia (26.1\%).

In 1186 pregnancies (21\%), one or more foetal complications occurred. In particular prematurity was prevalent (16\%). These rates were highest in patients with CMP (26\%), PAH (49\%), and AOP (21\%). In Supplementary material online, Figure S6, the occurrence of obstetric and foetal events is summarized per diagnostic group. Cardiovascular, and all obstetric and foetal outcomes varied according to $\mathrm{mWHO}$ categories (Supplementary material online, Figure S3).

\section{Discussion}

ROPAC is a prospective registry containing 5739 pregnancies in women with structural and IHD, PAH, and AOP. This is by far the largest registry of its kind ever undertaken. The overall maternal mortality rate in our study was $0.6 \%$, which is much higher than that observed in the normal pregnant population. ${ }^{11}$ The most important complication found in our registry is heart failure, which complicated $11 \%$ of pregnancies, of which $7 \%$ occurred for the first time in the first week postpartum. These results highlight that intensive management and monitoring of women at risk of heart failure is essential throughout pregnancy and also after delivery. 

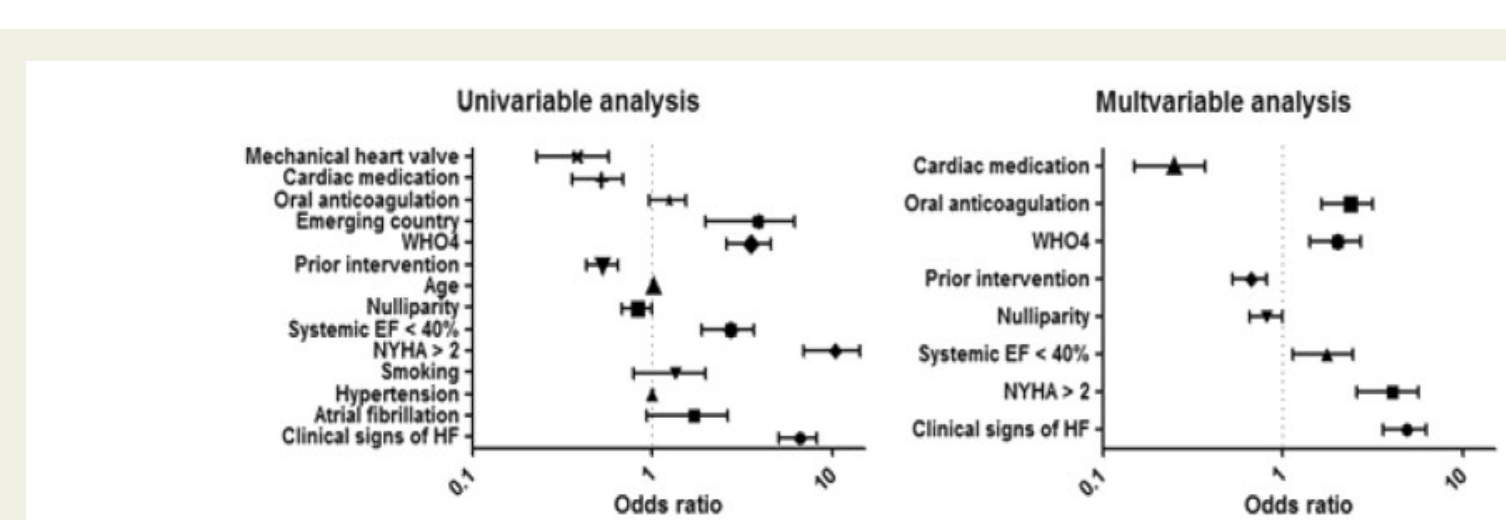

Figure 2 Univariable and multivariable logistic regression analysis for the primary endpoint or heart failure. All variables used in this regression were pre-pregnancy characteristics.

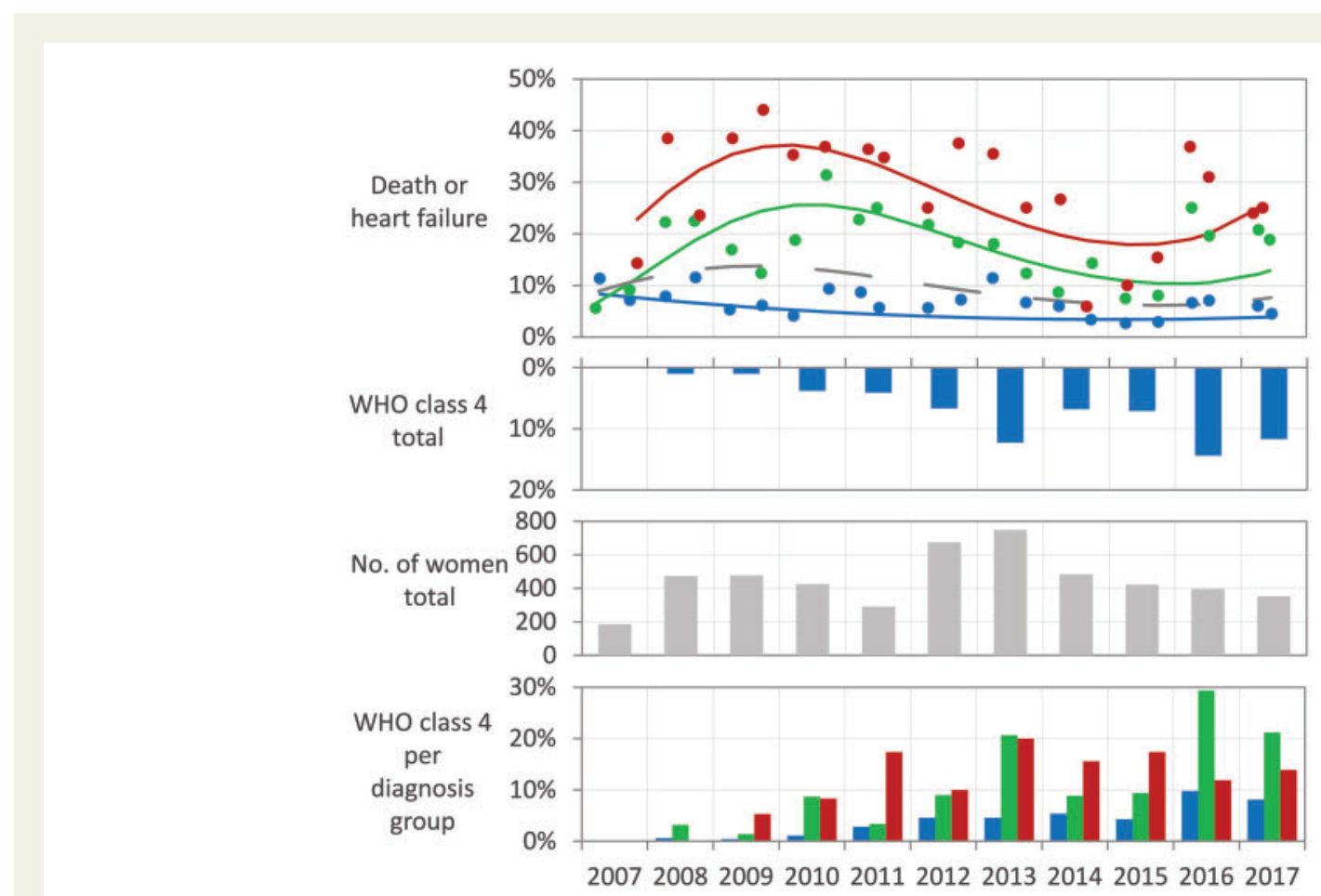

Figure 3 The trends over time in death or heart failure, for the overall cohort and for the three largest diagnosis groups. The number of total included pregnancies and the percentage inclusion of $\mathrm{mWHO}$ class $\mathrm{IV}$ in the corresponding year are shown below the figures, in total as well as for the diagnosis groups. The data points represent the number of death and/or heart failure per year. Time trends were analysed by linear mixed effect models with the logit link function (see Methods section). The model that we fitted for the overall cohort was as follows: logit (endpoint) $=-2.447+$ $0.524 \times \tau-0.130 \times t^{2}+0.008 \times t^{3}$, with $t=$ time since 1 January 2007. The significance of the respective regression coefficients was as follows: $<0.001,0.003,0.002,0.002$. Cardiomyopathy; $\bigcirc$, Valvular heart disease; O. Overall cohort;, , Congenital heart disease.

One of the WHO Millennium Development Goals was to reduce maternal deaths by 75\% between 1990 and 2015; this was partially successful, as the rate fell by $44 \% .^{3}$ The new Sustainable Development Goals have targeted a reduction in worldwide maternal mortality to $<70$ deaths per 100000 live births by $20300^{3}$ To achieve this target, the rate of decline in maternal mortality will have to increase to $7.5 \%$ per year. This is unlikely to be achieved unless the increasing contribution to mortality made by heart disease is reversed. Data from ROPAC can help by determining which patients are at high risk and identifying areas in which the greatest improvements can be achieved.

\section{Diagnostic groups: low-risk and high-risk patients}

The highest mortality/heart failure rates were found in women with PAH, CMP, and VHD as also described by previous series. ${ }^{12-20}$ The trends over time showed that especially in VHD and CMP there was a decrease in maternal mortality or heart failure, while in CONHD 


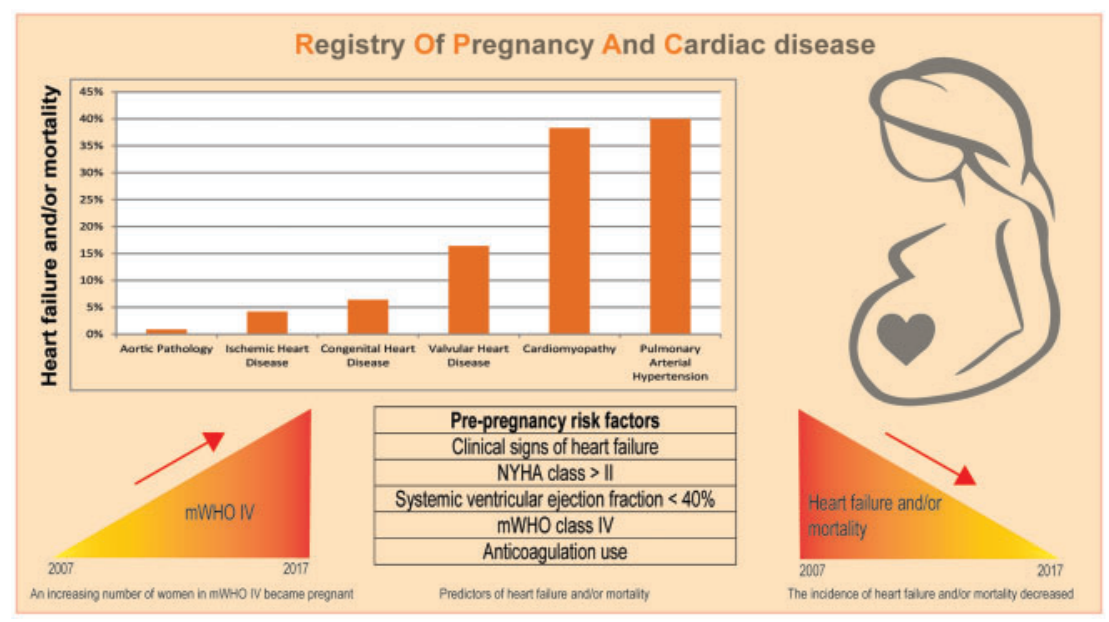

Take home figure From 2007 to 2018, pregnant women with heart disease were included in the Registry Of Pregnancy And Cardiac disease (ROPAC). During that time, the incidence of 'maternal death or heart failure' dropped, despite the inclusion of more seriously ill women (mWHO IV). Especially women with cardiomyopathies or pulmonary arterial hypertension were at risk of 'maternal death or heart failure'. Pre-pregnancy risk factors were signs of heart failure prior to pregnancy, NYHA class > II, systemic ventricular ejection fraction of below $40 \%$, $\mathrm{mWHO}$ class IV conditions and anticoagulation use.

the rate was and remained low. Our study emphasizes that patients with PAH are still, despite advances in management, a high-risk group and that they should be advised against pregnancy.

The mortality rate for the CMP group was $1.1 \%$ and heart failure occurred in $28 \%$. Current guidelines advise against pregnancy if the systemic ventricular EF is $<30 \%{ }^{12}$ Our data suggest that all patients with dilated $\mathrm{CMP}$, even with relatively preserved $\mathrm{EF}$, are high risk and should be counselled accordingly. ${ }^{21-23}$

Patients with CONHD constitute the largest subgroup within this registry and have a relatively favourable pregnancy outcome, ${ }^{10}$ with a mortality rate of $0.2 \%$. However, due to the heterogeneous nature of this group, the type and complexity of CONHD need to be taken into account. Indeed, the heart failure rate in the patients with complex CONHD was $13 \%$, while it was $5 \%$ and $6 \%$ for the simple and moderate defects, respectively. The vast majority of patients had their condition diagnosed and treated at a young age, allowing ample opportunity for pre-pregnancy counselling and optimization prior to pregnancy, perhaps accounting for the relatively good outcomes.

In the AOP group, the rate of dissection was $1.8 \%$ and we found a strikingly high rate of delivery by caesarean section (52\%). There are limited data on the effect of labour and active pushing on the risk of aortic dissection, and current guidelines are solely based on expert opinion. ${ }^{24-26}$ Many physicians feel safe when using caesarean section, however, using epidural anaesthesia with the avoidance of pushing might be as good or even better for mother and baby, ${ }^{27}$ but more research is clearly required to investigate the optimal mode and timing of delivery in these women. A dedicated ROPAC registry for patients with $A O P$ just started within the EORP, to further analyse the risks and outcomes during pregnancy.

A large proportion of patients with VHD had rheumatic heart disease (56\%). These women show a tendency to present late in pregnancy, meaning that those caring for them often only become aware of the condition when complications arise. ${ }^{28}$ This may explain the high rates of maternal mortality (1\%) and heart failure $(17 \%)$ in this group. Especially severe mitral stenosis is associated with high complication rates. ${ }^{28}$ Seven percent of patients with a mechanical valve suffered from valve thrombosis, of which $18 \%$ died. There is still no consensus with respect to the best anticoagulation strategy, ${ }^{29-32}$ another area where research is urgently required. Women with a mechanical prosthesis are currently classified as $\mathrm{mWHO}$ III. However, given the high rates of severe and potentially lethal complications and miscarriages, perhaps Class IV is more appropriate and a particular cautious approach is warranted to counselling these women and close observation with dedicated supervision is recommended when pregnancy occurs. In the recently published ESC guidelines on cardiovascular disease and pregnancy, women with mechanical prostheses are now advised to be referred to a tertiary care centre, because of these high complication rates. ${ }^{1}$ A dedicated ROPAC registry for patients with valvular prostheses also started in 2018, to specifically investigate which anticoagulation regimen is associated with the lowest risks and to further analyse the outcomes during pregnancy.

The women with IHD were typically older, were more often multipara and had surprisingly good maternal outcome, with no mortality and $4 \%$ heart failure. Evidence in this field is still very limited and these patients are often being approached with much caution and pregnancy being discouraged. Clearly larger series are required to facilitate better counselling.

The results from our study are in line with recommendations from the 2018 ESC guidelines for the management of cardiovascular diseases during pregnancy. ${ }^{1}$ Indeed all women with heart disease should be managed in a hospital. Women in $\mathrm{mWHO}$ Class I and II can be cared for in a local hospital and women in Class II-III in a referral hospital, while women in Class III and IV should be managed in specialized, tertiary centres by a specialized, multidisciplinary team. Pre-conceptional counselling is advised for women in all $\mathrm{mWHO}$ classes as it is associated with better outcome. 


\section{Clinical determinants of study endpoint}

Pre-pregnancy predictors of heart failure and/or mortality were signs of heart failure or NYHA $>I I$, systemic ventricular EF of $<40 \%$, $\mathrm{mWHO}$ IV, and anticoagulants use. This highlights the importance of pre-conception counselling and optimization of cardiac function before pregnancy. Some patients can benefit from adjusting or introducing medication to improve their cardiovascular status before pregnancy. The use of anticoagulation as a predictor for adverse outcome is likely to be explained only partly by the effect of the medication itself. The underlying reason for the medication, such as mechanical valves, arrhythmias or dilated CMP probably have an effect.

\section{Study endpoints over time}

A remarkable finding was that over the period of the study, an increasing number of pregnancies in women with $\mathrm{mWHO}$ IV disease were included. This is surprising since conventional advice to women in this high-risk group is to avoid pregnancy. This is not due to the later inclusion of patients with PAH and AOP since these groups were excluded from this analysis. Of course, this increase might be (partly) explained by selection of patients due to centre and country inclusion, but clustering within country and site was controlled for. While recommendations and guidelines are now available and often discussed with the patients, we cannot prevent women from choosing to become pregnant and we not infrequently encounter high-risk women who have become pregnant despite our advice. A further explanation of this change in risk profile is that physicians have become more comfortable with managing women with heart disease, feel better capable of dealing with their problems and have therefore modified their advice. Alternatively, it may simply reflect the existence of increasing numbers of high-risk patients in the population. Indeed, the first wave of patients with surgically corrected complex congenital heart defects such as women with a Fontan circulation are now reaching adulthood and have the wish to become pregnant. This increasing number of high-risk pregnancies is a challenge and requires careful management. Centralization of care for these patients may optimise outcome. It is also notable, that despite this increase in risk profile, there was not an increase in mortality with time. Supplementary material online, Figure S4 shows that there were around $11 \%$ of women in $\mathrm{mWHO} \mathrm{IV}$ in the years $2015-2017$, yet still the mortality was lower than in the beginning of the study period, when the proportion mWHO IV was only 1\%. In fact, from 2010 to 2011 onwards, the incidence of death or heart failure showed a significant decrease. This might indicate greater awareness of the specific problems and an improvement in the management of pregnant women with heart disease, which may be related to the publication in 2011 of the first ESC guideline on the management of pregnancy in women with cardiovascular disease. Although this may be a coincidence, it is possible that the well-publicized availability of this central resource has led to an increased awareness of the improvement in management. Of course, the improvement in outcome could also be associated with political, socioeconomic or access-to-healthcare factors. Our findings are mirrored by those of the United Kingdom report on maternal mortality which also shows a fall in mortality in recent years. ${ }^{2}$ Not surprisingly, we saw the greatest improvement in outcome in emerging countries, probably because this is where the mortality was highest and consequently, where the greatest improvement could be achieved.

\section{Limitations}

While ROPAC is prospective and the largest registry including all groups of heart disease, which describes real-life clinical practice, it is limited by several factors:

- Because we report only mortality up to one week our estimates are highly likely to have underestimated this component of the primary endpoint compared with other studies and this should be considered when making comparison.

- Many pregnant women with heart disease in our cohort were managed in specialized, tertiary centres with an interest in this field. The outcomes of other, non-tertiary centres may be different and caution is required in generalizing our results to the whole population.

- Although the major advantage of a prospective registry is the way in which it can document clinical reality, there might still be some form of selection bias present, as we cannot guarantee (although it was requested and stressed) that consecutive patients from all centres were included.

- Some countries and centres have included more patients than others. Furthermore, the number and constitution of participating centres varied over time, creating a heterogeneous cohort in which interpreting results is difficult. However, we adjusted for this in our analyses.

\section{Conclusions}

While pregnancy in women with heart disease in general is associated with increased risks of maternal mortality $(0.6 \%)$ and cardiovascular, obstetric, and foetal complications, many patients tolerate pregnancy well. Patients with $\mathrm{PAH}$ and CMP are at particularly high risk, while women with simple CONHD have relatively good outcomes. Pregnancy in women with low-risk conditions should not be discouraged, while clear and timely advice not to become pregnant should be provided to very high-risk women. Pre-pregnancy predictors for mortality and/or heart failure are NYHA class of $>I 1, m W H O ~ I V$, systemic ventricular EF of $<40 \%$, signs of heart failure, and the use of anticoagulants.

Until 2010, maternal mortality and/or heart failure increased. Thereafter, these rates declined, especially in emerging countries, despite increasing numbers of high-risk patients. Further studies are required to assess the optimal management of these patients, with particular emphasis on cardiac medication use, including anticoagulation regimes and mode of delivery.

\section{Supplementary material}

Supplementary material is available at European Heart Journal online.

\section{Acknowledgements}

Data collection was conducted by the EORP department from the ESC by Elin Folkesson Lefrancq as Project Officer; Viviane Missiamenou, Gérard Gracia, and Sebastien Authier as Data Managers. Overall activities were coordinated and supervised by $\mathrm{Dr}$ Aldo P. Maggioni (Scientific Coordinator). 


\section{Funding}

This work was supported from 'Zabawas Foundation' and 'De Hoop Foundation' in addition to the support from EORP is greatly acknowledged. Since the start of EORP, the following companies have supported the programme: Abbott Vascular Int. (2011-2014), Amgen Cardiovascular (2009-2018), AstraZeneca (2014-2017), Bayer AG (2009-2018), Boehringer Ingelheim (2009-2019), Boston Scientific (2009-2012), The Bristol Myers Squibb and Pfizer Alliance (2011-2019), Daiichi Sankyo Europe GmbH (2011-2020), The Alliance Daiichi Sankyo Europe GmbH and Eli Lilly and Company (2014-2017), Edwards (20162019), Gedeon Richter Plc. (2014-2016), Menarini Int. Op. (2009-2012), MSD-Merck \& Co. (2011-2014), Novartis Pharma AG (2014-2017), ResMed (2014-2016), Sanofi (2009-2011), SERVIER (2009-2018).

Conflict of interest: A.P.M. reports personal fees from Bayer, Novartis and Fresenius. W.P. reports personal fees from Pfizer. L.T. reports personal fees from Servier and CVIE Therapeutics. A.V. reports personal fees from Abbott Vascular and Cardiovalve. All outside the submitted work.

\section{References}

1. Regitz-Zagrosek V, Roos-Hesselink JW, Bauersachs J, Blomström-Lundqvist C, Cífková R, De Bonis M, lung B, Johnson MR, Kintscher U, Kranke P, Lang IM, Morais J, Pieper PG, Presbitero P, Price S, Rosano GMC, Seeland U, Simoncini T, Swan L, Warnes CA;ESC Scientific Document Group. 2018 ESC Guidelines for the management of cardiovascular diseases during pregnancy. Eur Heart J 2018; 39:3165-3241.

2. Knight M, Nair M, Tuffnell D, Shakespeare J, Kenyon S, Kurinczuk J], eds; on behalf of MBRRACE-UK. Saving Lives, Improving Mothers' Care-Lessons Learned to Inform Maternity Care from the UK and Ireland Confidential Enquiries into Maternal Deaths and Morbidity 2013-15. Oxford: National Perinatal Epidemiology Unit, University of Oxford; 2017

3. Alkema L, Chou D, Hogan D, Zhang S, Moller AB, Gemmill A, Fat DM, Boerma T, Temmerman M, Mathers C, Say L; United Nations Maternal Mortality Estimation Inter-Agency Group collaborators and technical advisory group. Global, regional, and national levels and trends in maternal mortality between 1990 and 2015, with scenario-based projections to 2030: a systematic analysis by the UN Maternal Mortality Estimation Inter-Agency Group. Lancet 2016;387:462-474.

4. Khan KS, Wojdyla D, Say L, Gulmezoglu AM, Van Look PF. WHO analysis of causes of maternal death: a systematic review. Lancet 2006;367:1066-1074.

5. MacDorman MF, Declercq E, Cabral H, Morton C. Is the United States Maternal Mortality Rate Increasing? Disentangling trends from measurement issues Short title: U.S. Maternal Mortality Trends. Obstet Gynecol 2016;128:447-455.

6. Khairy P, Ouyang DW, Fernandes SM, Lee-Parritz A, Economy KE, Landzberg MJ. Pregnancy outcomes in women with congenital heart disease. Circulation 2006; 113:517-524

7. Drenthen W, Boersma E, Balci A, Moons P, Roos-Hesselink JW, Mulder B], Vliegen HW, van Dijk AP, Voors AA, Yap SC, van Veldhuisen DJ, Pieper PG;ZAHARA Investigators. Predictors of pregnancy complications in women with congenital heart disease. Eur Heart J 2010;31:2124-2132.

8. Siu SC, Sermer M, Colman JM, Alvarez AN, Mercier LA, Morton BC, Kells CM, Bergin ML, Kiess MC, Marcotte F, Taylor DA, Gordon EP, Spears JC, Tam JW, Amankwah KS, Smallhorn JF, Farine D, Sorensen S; Cardiac Disease in Pregnancy (CARPREG) Investigators. Prospective multicenter study of pregnancy outcomes in women with heart disease. Circulation 2001;104:515-521.

9. Silversides CK, Grewal J, Mason J, Sermer M, Kiess M, Rychel V, Wald RM, Colman JM, Siu SC. Pregnancy outcomes in women with heart disease: the CARPREG II study. J Am Coll Cardiol 2018;71:2419-2430.

10. Roos-Hesselink JW, Ruys TP, Stein Jl, Thilen U, Webb GD, Niwa K, Kaemmerer $\mathrm{H}$, Baumgartner H, Budts W, Maggioni AP, Tavazzi L, Taha N, Johnson MR, Hall $\mathrm{R}$;ROPAC Investigators. Outcome of pregnancy in patients with structural or ischaemic heart disease: results of a registry of the European Society of Cardiology. Eur Heart J 2013;34:657-665.

11. EURO-PERISTAT Project, with SCPE, EUROCAT, EURONEOSTAT. European Perinatal Health Report. www.europeristat.com (11 March 2019).

12. European Society of Gynecology (ESG);Association for European Paediatric Cardiology (AEPC);German Society for Gender Medicine (DGesGM), RegitzZagrosek V, Blomstrom Lundqvist C, Borghi C, Cifkova R, Ferreira R, Foidart JM, Gibbs JS, Gohlke-Baerwolf C, Gorenek B, lung B, Kirby M, Maas AH, Morais J, Nihoyannopoulos P, Pieper PG, Presbitero P, Roos-Hesselink JW, Schaufelberger M, Seeland U, Torracca L;ESC Committee for Practice
Guidelines. ESC Guidelines on the management of cardiovascular diseases during pregnancy: the task force on the management of cardiovascular diseases during pregnancy of the European Society of Cardiology (ESC). Eur Heart J 2011;32:3147-3197.

13. Sliwa K, van Hagen IM, Budts W, Swan L, Sinagra G, Caruana M, Blanco MV, Wagenaar LJ, Johnson MR, Webb G, Hall R, Roos-Hesselink JW;ROPAC investigators. Pulmonary hypertension and pregnancy outcomes: data from the Registry Of Pregnancy and Cardiac Disease (ROPAC) of the European Society of Cardiology. Eur J Heart Fail 2016;18:1119-1128.

14. Pieper PG, Lameijer H, Hoendermis ES. Pregnancy and pulmonary hypertension. Best Pract Res Clin Obstet Gynaecol 2014;28:579-591.

15. Hemnes AR, Kiely DG, Cockrill BA, Safdar Z, Wilson VJ, Hazmi MA, Preston IR, MacLean MR, Lahm T. Statement on pregnancy in pulmonary hypertension from the Pulmonary Vascular Research Institute. Pulm Circ 2015;5:435-465.

16. Ladouceur M, Benoit L, Radojevic J, Basquin A, Dauphin C, Hascoet S, Moceri P, Bredy C, Iserin L, Gouton M, Nizard J. Pregnancy outcomes in patients with pulmonary arterial hypertension associated with congenital heart disease. Heart 2017;103:287-292.

17. Balint OH, Siu SC, Mason J, Grewal J, Wald R, Oechslin EN, Kovacs B, Sermer M, Colman JM, Silversides CK. Cardiac outcomes after pregnancy in women with congenital heart disease. Heart 2010;96:1656-1661.

18. Bendayan D, Hod M, Oron G, Sagie A, Eidelman L, Shitrit D, Kramer MR Pregnancy outcome in patients with pulmonary arterial hypertension receiving prostacyclin therapy. Obstet Gynecol 2005;106:1206-1210.

19. Jais $X$, Olsson KM, Barbera JA, Blanco I, Torbicki A, Peacock A, Vizza CD, Macdonald P, Humbert M, Hoeper MM. Pregnancy outcomes in pulmonary arterial hypertension in the modern management era. Eur Respir J 2012;40:881-885.

20. Bedard E, Dimopoulos K, Gatzoulis MA. Has there been any progress made on pregnancy outcomes among women with pulmonary arterial hypertension? Eur Heart J 2008;30:256-265.

21. Grewal J, Siu SC, Ross HJ, Mason J, Balint OH, Sermer M, Colman JM, Silversides CK. Pregnancy outcomes in women with dilated cardiomyopathy. J Am Coll Cardiol 2009;55:45-52.

22. Autore C, Conte MR, Piccininno M, Bernabo P, Bonfiglio G, Bruzzi P, Spirito P. Risk associated with pregnancy in hypertrophic cardiomyopathy. I Am Coll Cardiol 2002;40:1864-1869.

23. Goland S, van Hagen IM, Elbaz-Greener G, Elkayam U, Shotan A, Merz WM, Enar SC, Gaisin IR, Pieper PG, Johnson MR, Hall R, Blatt A, Roos-Hesselink JW. Pregnancy in women with hypertrophic cardiomyopathy: data from the European Society of Cardiology initiated Registry of Pregnancy and Cardiac disease (ROPAC). Eur Heart J 2017;38:2683-2690.

24. Sawlani N, Shroff A, Vidovich MI. Aortic dissection and mortality associated with pregnancy in the United States. J Am Coll Cardiol 2015;65:1600-1601.

25. Meijboom LJ, Vos FE, Timmermans J, Boers GH, Zwinderman AH, Mulder BJ. Pregnancy and aortic root growth in the Marfan syndrome: a prospective study. Eur Heart J 2005;26:914-920.

26. Braverman AC, Moon MR, Geraghty P, Willing M, Bach C, Kouchoukos NT. Pregnancy after aortic root replacement in Loeys-Dietz syndrome: high risk of aortic dissection. Am J Med Genet A 2016;170:2177-2180.

27. Ruys TP, Roos-Hesselink JW, Pijuan-Domenech A, Vasario E, Gaisin IR, lung B, Freeman LJ, Gordon EP, Pieper PG, Hall R, Boersma E, Johnson MR;ROPAC investigators. Is a planned caesarean section in women with cardiac disease beneficial? Heart 2015;101:530-536.

28. van Hagen IM, Thorne SA, Taha N, Youssef G, Elnagar A, Gabriel H, ElRakshy Y, lung B, Johnson MR, Hall R, Roos-Hesselink JW;ROPAC Investigators and EORP Team. Pregnancy outcomes in women with rheumatic mitral valve disease: results from the registry of pregnancy and cardiac disease. Circulation 2018;137:806-816.

29. van Hagen IM, Roos-Hesselink JW, Ruys TP, Merz WM, Goland S, Gabriel H, Lelonek M, Trojnarska O, AI Mahmeed WA, Balint HO, Ashour Z, Baumgartner H, Boersma E, Johnson MR, Hall R;ROPAC Investigators and the EURObservational Research Programme (EORP) Team. Pregnancy in women with a mechanical heart valve: data of the European Society of Cardiology Registry of Pregnancy and Cardiac Disease (ROPAC). Circulation 2015;132:132-142.

30. Vause S, Clarke B, Tower CL, Hay C, Knight M. Pregnancy outcomes in women with mechanical prosthetic heart valves: a prospective descriptive population based study using the United Kingdom Obstetric Surveillance System (UKOSS) data collection system. BJOG 2017;124:1411-1419.

31. Xu Z, Fan J, Luo X, Zhang WB, Ma J, Lin YB, Ma SH, Chen X, Wang ZP, Ou JS, Zhang $X$. Anticoagulation regimens during pregnancy in patients with mechanical heart valves: a systematic review and meta-analysis. Can J Cardiol 2016;32: 1248.e1-1248.e9.

32. Basude S, Hein C, Curtis SL, Clark A, Trinder J. Low-molecular-weight heparin or warfarin for anticoagulation in pregnant women with mechanical heart valves: what are the risks? A retrospective observational study. BJOG 2012;119: 1008-1013; discussion 1012-1013. 